\title{
Multiple Coronary Ostia and Their Clinical and Surgical Significance
}

\author{
Dr. Surekha Wamanrao Meshram (M.B.B.S, M.D), \\ Dr. Anjali Rai Ladia (M.B.B.S, M.D),Dr. V.P.Rukhmode(M.B.B.S, M.S), Dr. \\ Ujwal L. Gajbe (M.B.B.S, M.S) \\ Associate professor, Dept. of Anatomy Government Medical College, Gondia Maharashtra India \\ Assiatant Professor, Dept. of Anatomy Government Medical College, Gondia. Maharashtra India \\ Professor and Head, Dept. of Anatomy Government Medical College, Gondia. Maharashtra India \\ Professor and Head, Dept. of Anatomy Jawaharlal Nehru Medical College, Sawangi, Wardha \\ Maharashtra, India
}

\begin{abstract}
:
Background: Anomalous origin of multiple coronary ostia from a single coronary sinus are very rare findings. Proficiency in the anatomy of coronary arteries and their variations is significant for proper interpretation of the coronary angiographies, assessment of the complexity and result of coronary insufficiency as well as surgical myocardium revascularization. Anomalous coronary ostia has severe clinical manifestation including sudden death in young athelets so taking into consideration its importance this study is carried out to study in detail the normal and variant anatomy of coronary ostia and its clinical significance in the living subjects.

Method: This study is carried out in 50 embalmed human hearts by fine dissection method with the help of pointed forceps. We find out origin of multiple ostia of coronary arteries from a single coronary sinus. The courses of arteries arising from these anomalous ostia are also studied in detailed.

Result \& Conclusion: Very few data exist on the clinical relevance of different coronary arteries anomalies which necessitate a proper management and follow up protocol. The patho-physiological complexity, non specific manifestations and unclear relationship with myocardial ischemia, and sudden death due to anomalous coronary ostia attracted to do this study and apply this knowledge in living subjects to overcome the morbidity and mortality in them and to help the cardiologist during routine diagnostic work up for cardiac diseases and management of these diseases.
\end{abstract}

Key Words: Anomalous, Artery, Coronary arteries, Ostia,

\section{Introduction:}

The word coronary is derived from Latin word. It refers to crown like arrangement of all coronary arteries as they encircle the heart in atrioventricular sulcus. Anomalous coronary ostia are very rare anomalies detected in very less population. Knowledge of anomalies of coronary circulation is an increasing important component in managing congenital and acquired heart diseases.

Coronary vessels supply the heart with blood and supply nourishment to the heart. Atherosclerotic changes in these vessels are described as coronary heart disease. Congenital, inflammatory, metabolic and degenerative heart diseases may involve coronary circulation and increasingly complex cardiac surgical repairs demand more understanding to improve operative outcome.

According to the World Health Organization (WHO), coronary heart diseases constitutes the main cause of death in the industrial world. The main risk factors are lipid disorders, hypertension, diabetes, obesity, lack of physical activities and other disorders which cause functional impairment and damage to vascular cells. But, the risk factors don't explain the local distribution of atherosclerotic lesions. The pattern of this distribution corresponds to zones of disturbed flow with vortex formations and low velocity flow in coronary arteries. The anatomic details and pathophysiological patterns of most coronary artery anomalies are presently well known. On the contrary few data exist on the clinical relevance of different coronary arteries variation which necessitate a proper management and follow up protocol. Clinical invasive and interventional cardiologists often continue to encounter the coronary artery anomalies as incidental findings during routine diagnostic work up for other cardiac diseases.

Certain authors proposed that coronary arterial pattern were not fully established at the time of birth. Human adult heart has a higher incidence of existence of multiple ortifices than human fetal heart suggested that these ostia may developed after birth. 
Considering the significance of knowledge of coronary arterial pattern in cardiac surgeries and keeping in mind the ever evolving and yet unexplored facets of this subject the present study has been undertaken to shed more light on this topic.

Normally the anterior aortic sinus shows presence of one ostium of origin of right coronary artery and left posterior aortic sinus shows presence of one ostium of left coronary artery.

The present study reports anomalous origin of multiple coronary arteries from anomalous coronary ostia and shows light on their clinical significance.

This study is also important for interpretations of coronography, surgical revascularization of myocardium and embryological interpretations.

\section{Material \& Methods:}

The study is carried out in the Department of Anatomy, Jawaharlal Nehru Medical College, Sawangi (Meghe), Wardha. Total fifty hearts were obtained from cadavers of adult individual of both sexes, having age between 17-60 years. First the hearts were fixed in 10\% formalin.

Dissections conducted on heart included the removal of epicardium and subepicardial adipose tissue and the tracing of each artery. The dissections of ascending aorta was done and coronary arteries orgin was observed minutely. The ascending aorta was transversally sectioned approx. $1 \mathrm{~cm}$ above the commissures of the aortic leaflets. After that the aorta was longitudinally opened at level of the posterior aortic sinus (non coronary sinus) to enable the visualization and analysis of right and left aortic leaflets and their respective coronary ostia. Then the courses of coronary arteries arising from the anomalous ostia was traced minutely with the help of fine forceps. The most representative preparations were photographed.

\section{Aims And Objective:}

The present study was aimed at:

1. To study number of coronary ostia.

2. To study position of coronary ostia in relation with aortic sinuses.

3. To study the origin of coronary arteries arising from coronary ostia.

4. To study the courses of coronary arteries arising from anomalous ostia.

5. To study clinical significance of anomalous coronary ostia.

6. To apply this knowledge in living subjects during certain diagnostic procedures and cardiac surgeries.

\section{Results:}

In the present study out of 50 hearts, following observations were recorded and presented under following headings:

Site of ostia

Number of ostia

Arteries arising from anaomalous ostia

\section{Site of ostia}

Normally the right coronary artery arises from right aortic sinus, the left coronary artery from the left posterior aortic sinus, the position of the ostia of origin being within the sinus of valsalva or at the junction of the sinus and tubular portions of the aorta.

In the present study ostium for the left coronary artery in all 50 hearts were seen situated in the left posterior aortic sinus region.

In right coronary artery ostium was seen originating in relation to anterior aortic sinus or sinuaortic junction in 48 cases (96\%). In two specimens right coronary artery was seen originating from Right Posterior Aortic Sinus (RPAS). Fig no.1 \& Table no.I

Table I: Showing site of origin of coronary arteries

\begin{tabular}{|l|l|l|l|}
\hline & Site of origin & No. of hearts & Percentage of hearts \\
\hline RCA & Origin related to AAS & 48 & $96 \%$ \\
\hline & Origin related to RPAS & 2 & $4 \%$ \\
\hline LCA & Origin related to LPAS & 50 & $100 \%$ \\
\hline
\end{tabular}




\section{Cut secton of aorta showing opening of RCA from right posterior aortic sinus}
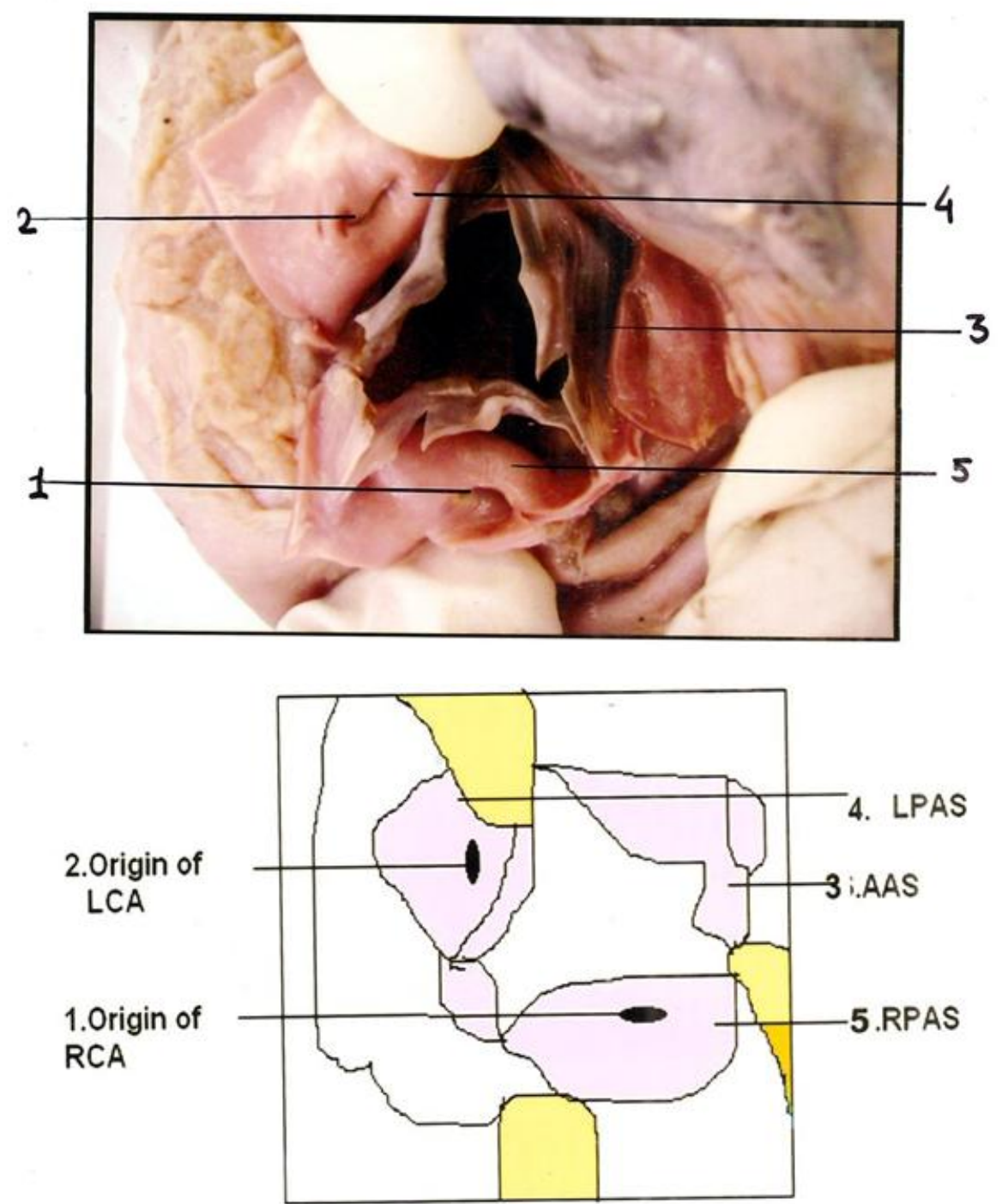

Fig. No. 1

2.No of ostia: out of 50 hearts, 5 hearts showed more than one ostium in the anterior aortic sinus region.

(a)Two ostia : Two specimens showed two ostia in the anterior aortic sinus, one for right coronary artery and one for right conus artery respectively (Fig No. 2). The right conus artery arising separately from anterior aortic sinus is also called as third coronary artery. (b)Three ostia: One specimen has 3 separate ostia in the anterior aortic sinus. They were for the right contrary artery, right conus artery and a vasa vasorum to the pulmonary trunk respectively. (Fig No.3) (c) Four ostia : Two specimens had 4 ostia in the anterior aortic sinus.

They were for the right coronary, SA nodal artery, right conus artery and a vasa vasorum to pulmonary trunk respectively. (Fig No. 4)

Table No. II The following table detects the extra ostia seen in AAS.

\begin{tabular}{|l|l|l|}
\hline Coronary artery & No. of hearts they were found & Percentage \\
\hline $3^{\text {rd }}$ coronary artery & 2 & $4 \%$ \\
\hline $\begin{array}{l}\text { RCA, RCoA, vasa vasorum of pulmonary } \\
\text { trunk }\end{array}$ & 1 & $2 \%$ \\
\hline $\begin{array}{l}\text { RCA, RCOA, SA nodal artery \& vasa } \\
\text { vasorum of pulmonary trunk }\end{array}$ & 2 & $4 \%$ \\
\hline
\end{tabular}


Anterior aortic sinus showing openings of RCA \& RCoNA
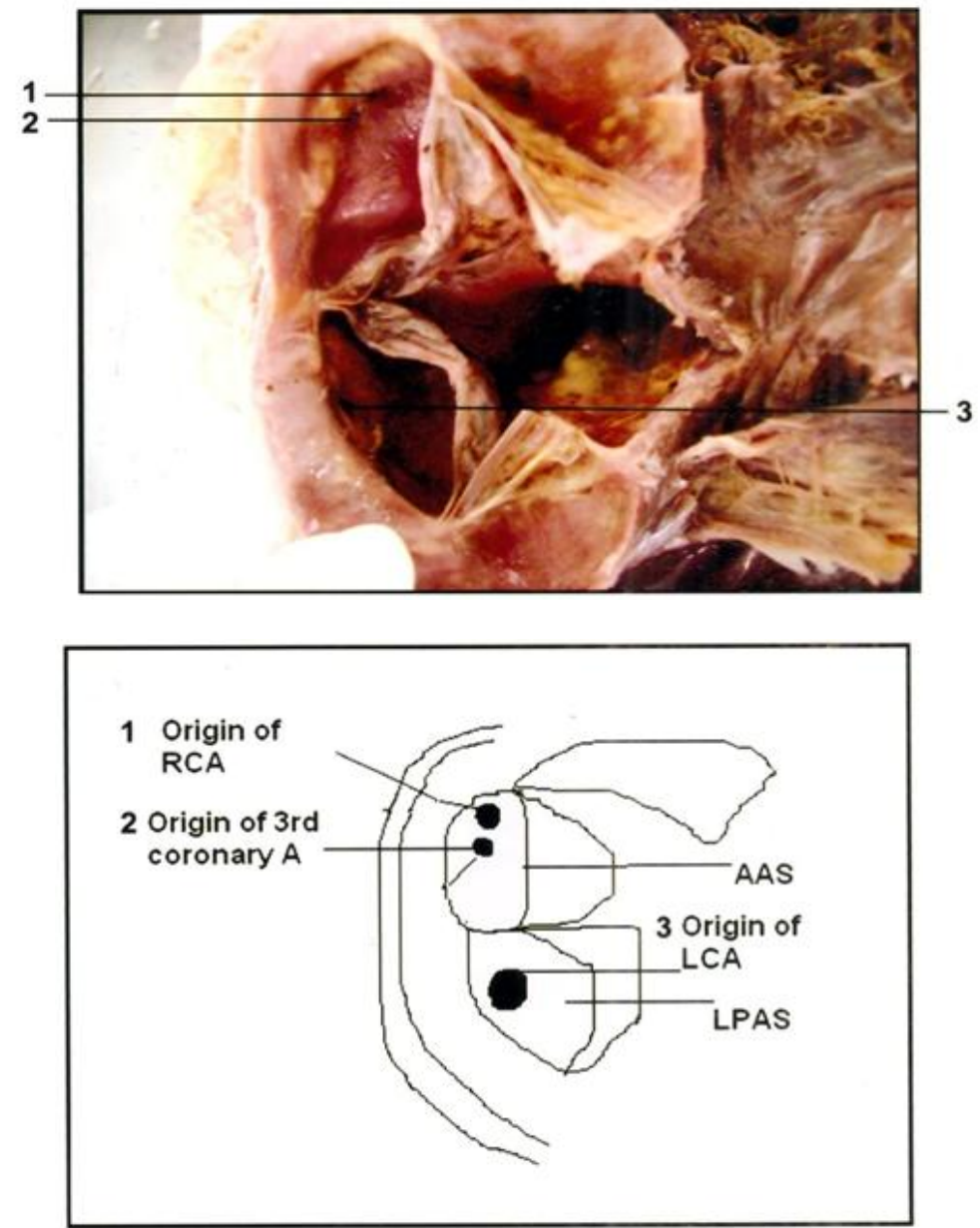

Fig.3

Anterior aortic sinus showing three openings

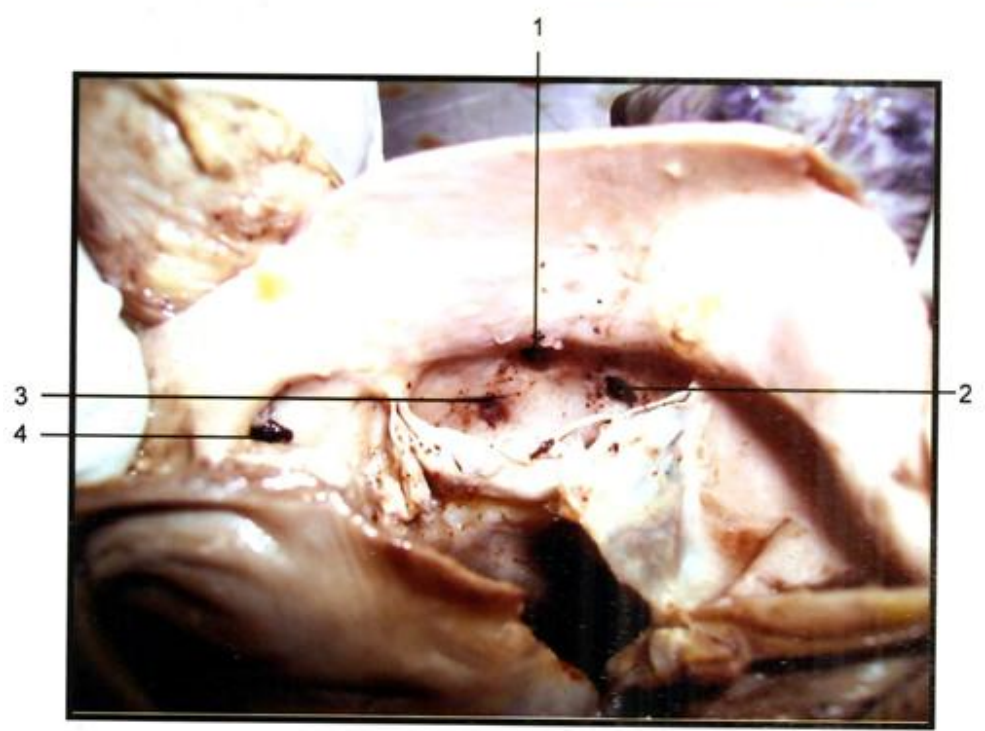




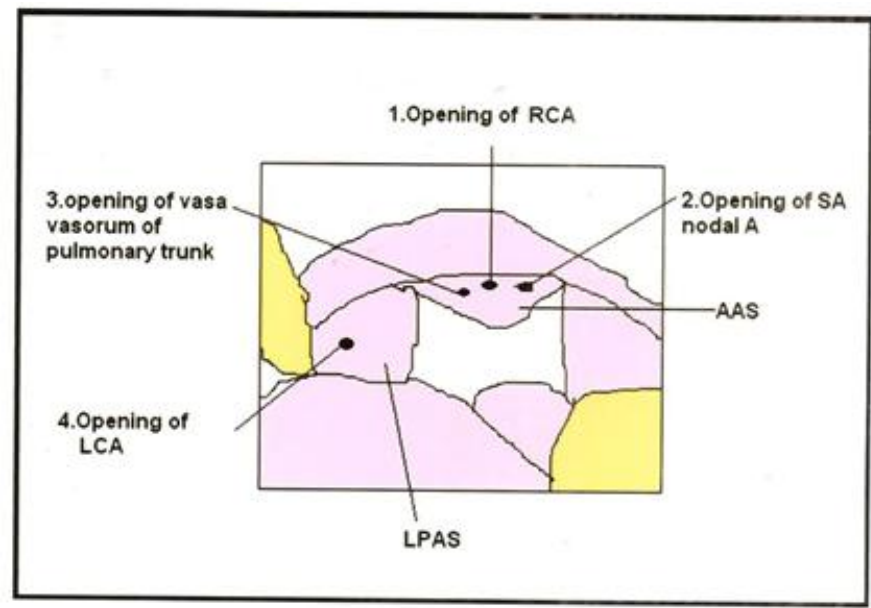

Fig.4

\section{Anterior aortic sinus showing four openings}
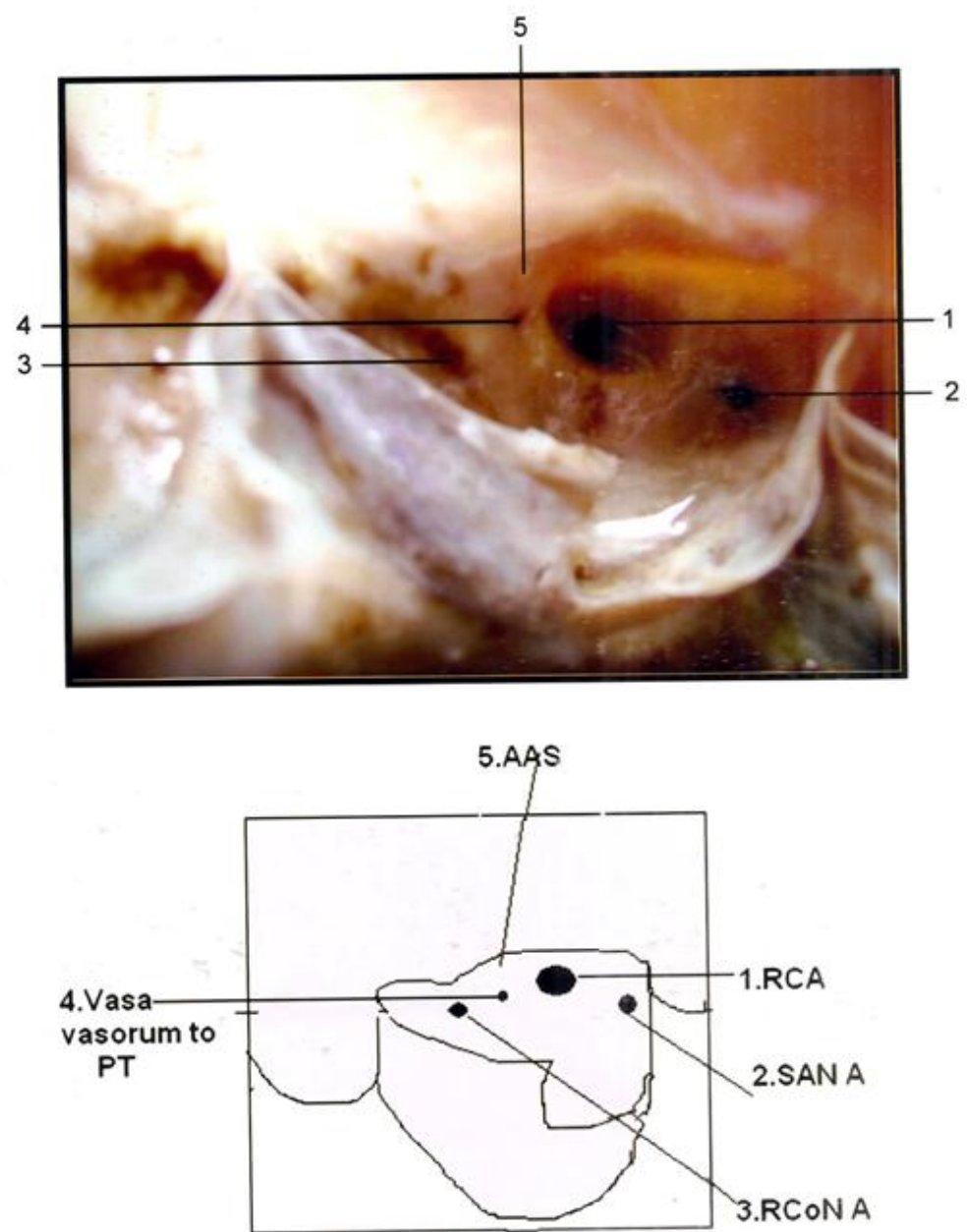

Detailed study of coronary arteries arising from the four multiple ostia.

Anterior surface of heart showing right coronary artery, sinuatrial nodal artery, right conus artery and vasa vasorum to pulmonary trunk. (Fig.No. 5)

Form the figure we can clearly marked out the RCA which runs in the anterior part of right atrioventricular groove, SA nodal artery which runs between the right atrium and ascending aorta and the supply the SA node. The third artery is the right conus artery which winds the infundibulum of pulmonary trunk. 
The fourth artery is the vasa vasorum to pulmonary trunk which is the small twig supplying nourishment to pulmonary trunk.
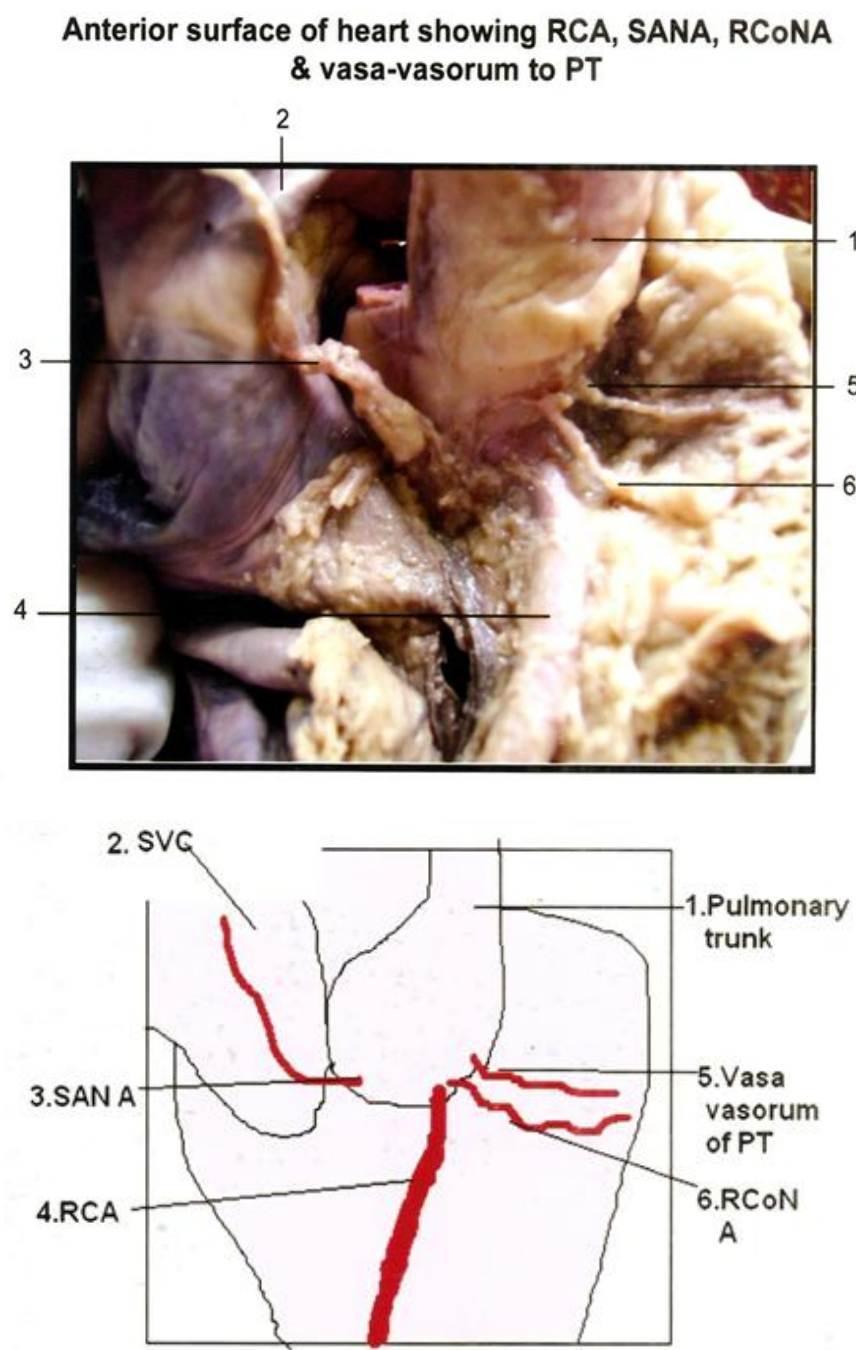

Fig. No. 5

IV. Discussion:

The variations of the origin of coronary arteries and presence of multiple anomalous ostia are rare and could cause certain clinical consequences. When multiple ostia are observed in the anterior aortic sinus, the most common variation observed is an accessory orifice for right conus artery. It is also called as third coronary artery. The $3^{\text {rd }}$ coronary artery usually forms an anastomosis with the likewise branch of left coronary artery. This anastomosis lies on the distal part of the pulmonary trunk and is known as the "vieussens arterial ring". The functional significance of this anastomosis is still under question. However, several authors have proposed that it finctions as an important collateral path between right and left coronary arteries. Morphometic characterization of this artery is important for interpretation of coronorgraphy and surgical revascularization of myocardium. Following table (III) reports the incidence of $3^{\text {rd }}$ coronary artery as reported by various authors and compared with present study.

\begin{tabular}{|l|l|}
\hline Author & Percentage of incidence \\
\hline Blake (1964) & $23.50 \%$ \\
\hline Miyazaki (1986) & $36.50 \%$ \\
\hline Regi (2003) & $33.80 \%$ \\
\hline Gray's anatomy (38 ${ }^{\text {th }}$ edition) & $50 \%$ \\
\hline Stankovic (2004) & $54.80 \%$ \\
\hline Koerig (2006) & $50 \%$ \\
\hline Present study (2008) & $10 \%$ \\
\hline
\end{tabular}


Several authors have reported multiple supernumerary ostia in the anterior aortic sinus.

Following table (IV) shows anomalous origins of different arteries from aortic and pulmonary sinuses reported by different authors and the present study.

\begin{tabular}{|l|l|}
\hline Authors & Anomalous presence of ostia \\
\hline Mc Alpine 1975 & From AAS : SA nodal artery. right ventricular branch \\
\hline Das 1986 & Form AAS: Anterior interventricular artery. \\
\hline Waller 1995 & $\begin{array}{l}\text { Form AAS: duplicate Anterior interventricular artery, Left } \\
\text { coronary artery, duplicate conal arteries }\end{array}$ \\
\hline Wei Li 2003 & Form Pulmonary trunk: Anterior interventricular artery. \\
\hline Shirani 2004 & Form AAS: Circumflex A \\
\hline Francisco 2005 & From AAS: Anterior interventricular artery, \\
\hline Ishizawa 2006 & From AAS:Left Coronary Artery \\
\hline Present study & $\begin{array}{l}\text { From AAS: SA nodal artery, right conus artery, vasa vasorum to } \\
\text { pulmonary trunk. }\end{array}$ \\
\hline
\end{tabular}

The importance of anomalous origin of arteries are:

1. During open heart surgeries, it is very difficult to cannaulate these vessels, which arises from the anomalous ostia.

2. While performing conronary arteriography and angiography a preliminary aortic root injection of dye must be given to locate exact no. of orifices and coronary arteries so that fatal outcomes can be prevented.

3. The anomalous origin of SA nodal artery cause disturbance of the arterial supply to SA node during cardiac surgery, particularly during atriotomies and the surgical correction of certain valvular disorders and congenital malformations which expose the suinuatrial node.

4. The multiple coronary ostia may be associated with cardiac abnormalities like hypertrophic cardiomyopathy and rarely associated with congenital coronary anomalies.

5. Through knowledge of existence of such multiple ostia is important to correctly interprete the angiographic findings.

Following table $(\mathbf{V})$ represents the ectopic origin of coronary artery from anomalous ostia and related pathology.

\begin{tabular}{|c|c|c|c|}
\hline Sr. No & Anomalous ostia & Anatomy & Pathophysiology \\
\hline 1. & $\begin{array}{l}\text { Ectopic origin of LCA } \\
\text { from right aortic sinus }\end{array}$ & $\begin{array}{l}\text { LCA arises from right sinus and passes } \\
\text { anterior or posterior to aorta or between } \\
\text { the assending aorta and pulmonary trunk. }\end{array}$ & $\begin{array}{l}\text { Potential compression of single coronary } \\
\text { vessel if it passes between Aorta and PT } \\
\text { with episodic ischemia, mypcardial } \\
\text { infarction \& sudden death }\end{array}$ \\
\hline 2. & $\begin{array}{l}\text { Ectopic origin of Left } \\
\text { circumflex from RCA }\end{array}$ & $\begin{array}{l}\text { The Left circumflex arises from the right } \\
\text { aortic sinus or proximal to RCA } \\
\text { posterior to Aortic course }\end{array}$ & $\begin{array}{l}\text { No hemodynamic impairment. Accidental } \\
\text { compression during valve replacement. }\end{array}$ \\
\hline 3. & $\begin{array}{l}\text { Separate orgin of } \\
\text { circumflex } \text { and } \\
\text { anterior descending }\end{array}$ & $\begin{array}{l}\text { Left circumflex and Left anterior } \\
\text { descending arteries arises from adjacent } \\
\text { separate ostia in the left aortic sinus }\end{array}$ & nic impairment \\
\hline 4. & $\begin{array}{l}\text { Ectopic origin of SA } \\
\text { nodal artery from Right } \\
\text { aortic sinus }\end{array}$ & $\begin{array}{l}\text { SA nodal artery after arising from aorta } \\
\text { directly goes the SA node and supplies it }\end{array}$ & No hemodynamic impairment \\
\hline 5. & $\begin{array}{l}\text { Ectopic origin of Right } \\
\text { conus artery from Right } \\
\text { aortic sinus }\end{array}$ & $\begin{array}{l}\text { It is called as } 3^{\text {rd }} \text { coronary artery and } \\
\text { after arising from aorta winds the } \\
\text { infundibulum of Pulmonary trunk }\end{array}$ & $\begin{array}{l}\text { It forms the separate path of anastomosis } \\
\text { between right coronary artery and left } \\
\text { coronary artery }\end{array}$ \\
\hline
\end{tabular}

The presence of multiple ostia has not been associated with clinical symptoms as per reported in literature.

To confirm the clinical association between anomalous ostia and pathophysiological conditions this correlation needs to be studied in live subjects who are investigated for multiple ostia by non invasive techniques like computed tomography. Individual which are detected to be having multiple ostia should be followed up regularly to watch out for any related symptoms of angina, myocardial infarction, left ventricular dysfunction, myocardial stunning, paroxysmal AV blockade etc. Although this process would be very expensive, impracticable and time consuming it will eliminate any selection bias associated with cardiac patient and help to confirm any association between presence of multiple ostia \& clinical symptoms.

\section{Acknowledgement:}

This study was supported by Datta Meghe Institute of Medical Sciences University, Nagpur, India. Thanks are due to Dr. Vedprakash Mishra, Vice-chancellor, DMIMS University and Dr. S.R. Joharapurkar, Director, DMDPG- MER for keen interest and encouragement; Dr. S.S. Patel, Dean, JN Medical College, Wardha, for cooperation. 


\section{References:}

[1]. Alexander RW and Griffith GC (1956). Anomalies of the coronary arteries and their clinical significance. Circulation 14: 800-805.

[2]. Aggarwal P, Kazerooni EA.Dual left anterior descending coronary artery.CT findings. A J R, AM J 2008 ;191 :1698-1701

[3]. Angelini P (1989). Normal and anomalous coronary arteries: Definitions and classification. Am Heart J, 117: $418-434$.

[4]. Bekedam, M.A. and Vligen, H.W. (1999) : Diagnosis and management of anomalous origin of right coronary artery from the left coronary sinus. International Journal of cardiologic Imaging 15 (3) : 253 - 258.

[5]. Caetano, A. G and Lopes, A.C. (1995) : Critical analysis of the clinical and surgical importance of the variations in the origin of sino-artrial node artery of the ssssssshuman heart. Rev. Assoc Med Brass 41 (2) : 94 - 102.

[6]. Engel, H.J. and Torres, C. (1975) : Major variations in anatomical origin of the coronary arteries-angiographic observations in 4,250 patients without associated congenital heart disease. Cathet. cardiovascular Diagnosis 116 ( 5) : 157-169.

[7]. Legubrrier A. Calmat A, honnart F and Cabrol C(1976). Variations anatomiques des orifices coronariens aortiques. Bull Ass Anat, 60: 721-731.

[8]. Miyazaki M, Kato M. Third coronary artery: its development and function. Acta Cardiol. (1988); 43 (4): $449-57$.

[9]. Schlesigner, M.J and Zoll, P.M. (1949) : The conus artery - a third coronary artery. American Heart Journal. $38: 823$.

[10]. Schlesinger MJ, Zoll PM and Wessler S(1949). The conus artery: A third coronary artery. Am. Heart J, 38: 823-836.

[11]. Waller BF (1983). Five coronary ostia: Duplicate left anterior descending and right conus coronary arteries. Am J Cardiol, 51:1562

[12]. Allwork SP, (1987). The applied anatomy of the arterial blood supply to the heart in man, J. Anat. 153

[13]. Angelini P (2002). Coronary artery anomalies - current clinical issues: definitions, classification, incidence, clinical relevance, and treatment guidelines. Tex Heart Inst J; 29:271-8.

[14]. Ayer AA,Rao YG. (1957) A radiographic investigations of the coronary arterial pattern in human hearts. J Anat Soc India;6 :63-67

[15]. Banchi A (1904). Morfalogia delle arteriae coronariae cordis. Arch ital Anat Embriol; 87-164. (Quoted byJ Reig Villaionga in 2003)

[16]. Baroldi G, Mantero O, Scomazzoni G (1956). The collaterals of the coronary arteries in normal and pathologic heart. Circ Res 4 :223-229(Gray's Anotomy S^edition; Coronary Arteries; Edinburgh,Churchill Livingstone ;pg 1505-1510)

[17]. Beach L, Burke A, Chute D, Virmani R (2001 April) (. Anomalous origin of four coronary ostia from the right Sinus of Valsalva in a patient of four Hypertropic Cardiomyopathi. Archives of pathological and laboratory Medicine, 125 (11):1489-1490.

[18]. CHEITLIN MD, DE, CASTRO C and MCALLISTER HA (1974). Sudden death as a complication of anomalous left coronary origin from the anterior sinus of valsalva. A not-so-minor congenital anomaly. Circulation, 50:780-787.

[19]. DiDio, L. J. A. \& WAKEFIELD, T.W. (1972). Origin, classification, nomenclature and incidence of the atrial arteries in normal human hearts, with special reference to their clinical importance. Acta Cardiologica 27, 565.

[20]. Jones AM. The coronary circulation in health and disease. The practitioner 1958; 180: 159-16623. May A M. Surgical Anatomy of coronary arteries. Dis chest 1960;38:645-657

[21]. Kimbiris D, Iskandrian AS, Segal BL, Bemis C. (1978) ( Anomalous aortic origin of the coronart arteries. Circulation;58:606-14

[22]. Koizumi, M, Kawai, K, Honma, S, Kodma (2000), K. Anatomical study of single coronary arterty with special reference to the various distribution patterns of bilateral coronary arteries. Ann ANAT;182:549-57

[23]. Khan NUA, Ahmed,S, Miller MJ. Int J Angiol 2004; 13:210-212

[24]. Moore KL,Dalley AF. Clinlcally Oriented Anatomy . $5^{\text {th }}$ edition Baltimore; Lippincott Williams \& Wilkins 2006: 156-9

[25]. Niwayama H, Morooka S, Takaoka N, et al. (1991) Hypertrophic cardiomyopathy associated with anomalous origin of the left coronary artery from right sinus of Valsalva. Kokyu To Junkun.;39;613

[26]. Schlesinger MJ, Zoll PM, Wessler S.( 1949;) The conus artery: A Third coronary artery. Am Heart J 38;823-836

[27]. Serino W, Sigwart U (1998). Septal ablation in a patient with hypertrophic obstructive cardiomyopathy and a unique variant of anomalous origin of the left coronary artery. Heart.;79:629-630

[28]. Stankovik, Jesic (2004). Morphometric characteristics of the conal coronary artery. MJM.:8:2-6.

[29]. Standring (chief editor, Grays Anatomy. In heart and great vessels.39 th edition.Edinburg, London.Elsevrchier, Churchill Livingstone 2005;1014-18

[30]. Surucu HS, Karahan ST,( 2004) Tanyeli E Saudi Med J; 25 :177-181 